\title{
Spotlight on ponatinib in the treatment of chronic myeloid leukemia and Philadelphia chromosome- positive acute lymphoblastic leukemia: patient selection and perspectives
}

This article was published in the following Dove Press journal: Blood and Lymphatic Cancer:Targets and Therapy

\section{Theodora Anagnostou}

Mark R Litzow

Mayo Clinic Rochester, Rochester, MN, USA
Correspondence: Mark R Litzow Mayo Clinic Rochester, 200 First Street, Rochester, MN 55905, USA

Tel + I 5072660688

Email Litzow.Mark@mayo.edu

\begin{abstract}
Ponatinib, a third-generation tyrosine kinase inhibitor that inhibits BCR/ABL independent of the mutation status, is currently approved for the treatment of patients with chronic myeloid leukemia or acute lymphoblastic leukemia that are either resistant or unable to tolerate another tyrosine kinase inhibitor. Its US Food and Drug Administration approval was based on results from long-term follow-up of the pivotal Phase II PACE trial, which demonstrated deep and durable molecular responses in the treated patients. Despite the remarkable responses, ponatinib has been associated with high frequency of severe vascular events, which led to its withdrawal from the market in 2013. Following analysis of the risk factors of patients who developed vascular side effects, ponatinib was reintroduced in the market 1 year later with specific dose-reduction recommendations and carrying a black box warning. Thus, careful patient selection with identification of patients whose potential benefit from ponatinib exceeds the potential risks associated with its use is crucial. Ongoing and future studies are focusing on earlier detection of mutations, strategies to minimize side effects, and potential expansion of the treatment indications. Clinical trials testing the safety and efficacy of ponatinib as frontline therapy are ongoing.
\end{abstract}

Keywords: ponatinib, acute lymphoblastic leukemia, chronic myeloid leukemia, patient selection

\section{Introduction}

The Philadelphia $(\mathrm{Ph})$ chromosome forms as a result of a reciprocal translocation between the $B C R$ gene on chromosome 22 and the $A B L 1$ gene on chromosome 9. The product of this fusion is a constitutively active tyrosine kinase that drives proliferation. ${ }^{1,2}$ Different constructs of the $\mathrm{Ph}$ chromosome are found in chronic myeloid leukemia (CML) and $20 \%-30 \%$ of cases of adult acute lymphoblastic leukemia (ALL). The presence of the $\mathrm{Ph}$ chromosome in ALL $(\mathrm{Ph}+\mathrm{ALL})$ confers a poor prognosis and is more common in older adults. ${ }^{3-6}$

The treatment for Ph-positive malignancies has changed significantly in the last few years owing to the introduction of multiple tyrosine kinase inhibitors (TKIs). Imatinib was the first TKI to be tested in CML, and it led to complete cytogenetic remission (CCyR) rates of over $80 \%$ when compared to interferon in the IRIS trial. ${ }^{7}$ However, $20 \%-30 \%$ of patients develop either primary or secondary resistance to imatinib. ${ }^{8}$ Thus, second-generation TKIs, including dasatinib and nilotinib, have been developed, and they are more effective in achieving molecular responses and reducing 
progression. ${ }^{9,10}$ In ALL, since the introduction of TKIs, the number of patients who undergo allogeneic stem cell transplantation (ASCT) while in complete hematologic response (CHR) or major molecular response (MMR) has increased significantly, leading to improved transplant outcomes. ${ }^{11,12}$

Ponatinib, a third-generation TKI that is 520 times more potent than imatinib, inhibits both wild-type and mutant $B C R-A B L 1$, including the T315I mutation, which results from a threonine to isoleucine substitution at position 315 of the $A B L$ gene. Similar to imatinib and nilotinib, ponatinib competes with adenosine triphosphate for the binding of the DFG-out conformation of the BCR-ABL tyrosine kinase. ${ }^{13,14}$ In addition, it causes inhibition of vascular endothelial growth factor receptor (VEGFR), platelet-derived growth factor receptor (PDGFR), fibroblast growth factor receptor (FGFR), sarcoma (SRC) kinase, stem cell growth factor receptor (KIT), rearranged during transfection (RET), fmslike tyrosine kinase 3 (FLT3) (Table 1). ${ }^{14}$ Ponatinib received

Table I Inhibition of kinases by different TKIs approved for the treatment of CML and/or ALL

\begin{tabular}{llllll}
\hline Kinase & Imatinib & Dasatinib & Nilotinib & Bosutinib & Ponatinib \\
\hline ABLI & $X$ & $X$ & $X$ & $X$ & $X$ \\
T3I5I & & $X$ & $X$ & & $X$ \\
FGFR & $X$ & $X$ & & $X$ \\
VEGFR & & & $X$ & & $X$ \\
PDGFR & $X$ & $X$ & $X$ & $X$ & $X$ \\
KIT & $X$ & $X$ & $X$ & & $X$ \\
FLT3 & $X$ & & $X$ & $X$ & $X$ \\
SRC & & $X$ & $X$ & & $X$ \\
\hline
\end{tabular}

Note: Over $50 \%$ inhibition is indicated by $X$.

Abbreviations: ALL, acute lymphoblastic leukemia; CML, chronic myeloid leukemia; TKIs, tyrosine kinase inhibitors; $A B L I$, abelson murine leukemia viral oncogene homolog I; FGFR, fibroblast growth factor receptor; VEGFR, vascular endothelial growth factor receptor; PDGFR, platelet-derived growth factor receptor; KIT, stem cell growth factor receptor; FLT3, fms-like tyrosine kinase 3; SRC, sarcoma kinase. accelerated approval by the US Food and Drug Administration (FDA) in 2012 for the treatment of patients with CML who had failed or could not tolerate an earlier generation TKI. This was based on results from early phase trials that demonstrated major cytogenetic response (MCyR) rates of over $70 \%$ in heavily pretreated patients. ${ }^{15,16}$ However, in 2013 , the drug was temporarily suspended by the FDA because of its high frequency of cardiovascular events, and the EPIC trial that was testing ponatinib for frontline therapy of newly diagnosed chronic phase CML was interrupted. Ponatinib was reintroduced in the market with specific dose-reduction recommendations 1 year later after a retrospective analysis of patients who took part in the Phase I and II studies identified preexisting conditions as risk factors for vascular side effects. ${ }^{17}$ Although ponatinib now carries a black box warning of vascular risks, it leads to deep and durable responses irrespective of mutation status.

\section{Efficacy of ponatinib in CML}

Prior to ponatinib approval, patients with the T315I mutation had poor prognosis with a median overall survival (OS) of 4 years following the development of resistance (Figure 1). ${ }^{18}$ The T315I mutation is found in $20 \%$ of patients with resistant or relapsed $\mathrm{CML},{ }^{19}$ and no mutations that confer resistance to ponatinib have been identified. ${ }^{20}$ The main clinical trials testing ponatinib in CML and ALL are summarized in Table 2.

Ponatinib was initially tested in a Phase I clinical trial of 60 patients with CML, most of whom had received treatment with at least two prior TKIs. Among the 43 patients who were in chronic phase, 98\% achieved CHR and $72 \%$ MCyR. ${ }^{15}$ All the 12 patients with the T315I mutation achieved CHR and 92\% achieved an MCyR. This was followed by the Phase II PACE trial in which 449 heavily
A

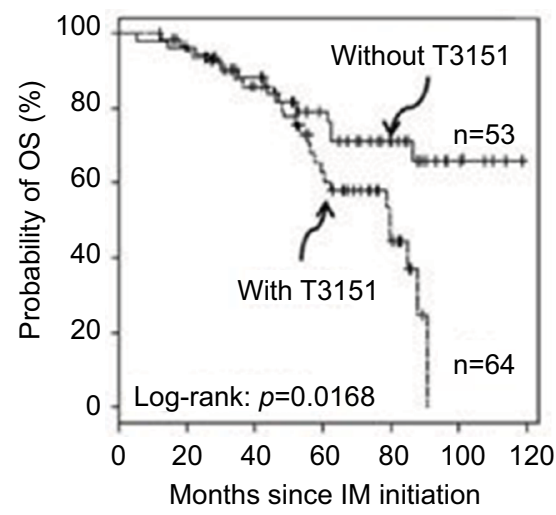

B

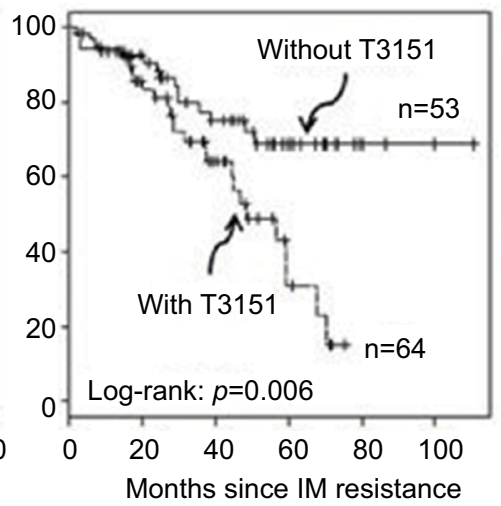

C

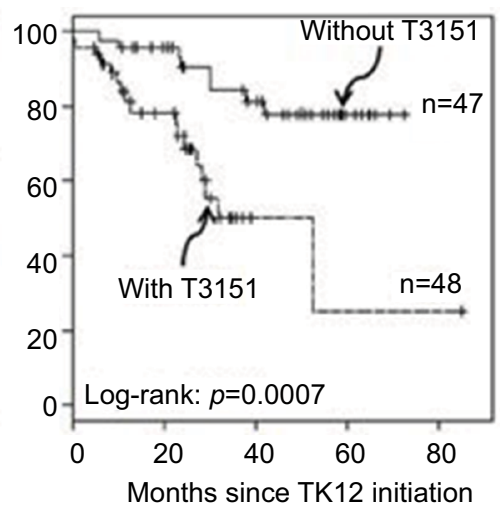

Figure I Overall survival (OS) of chronic phase CML patients resistant to IM, since IM initiation (A), since IM resistance (B), and since TKI2 initiation (C) in months according to $\mathrm{T} 315 \mathrm{I}$ status (dashed line represents patients with T3I5I mutation, plain line represents patients without T3I5I mutation).

Notes: n, number of patients. Reproduced with permission from Nicolini FE, Ibrahim AR, Soverini S, et al. The BCR-ABLT3I5I mutation compromises survival in chronic phase chronic myelogenous leukemia patients resistant to tyrosine kinase inhibitors, in a matched pair analysis. Haematologica. 20I3;98(I0):I5I0-15I6. ${ }^{18}$

Abbreviations: CML, chronic myeloid leukemia; IM, imatinib; TKI, tyrosine kinase inhibitor. 
Table 2 Summary of main clinical trials testing ponatinib in CML and ALL

\begin{tabular}{|c|c|c|c|c|c|c|c|}
\hline Disease & Reference & Phase & Regimen & $\begin{array}{l}\text { Study } \\
\text { population }\end{array}$ & Outcomes & Vascular SEs & $\begin{array}{l}\text { Most common } \\
\text { SEs }\end{array}$ \\
\hline \multirow[t]{4}{*}{$\mathrm{CML}$} & $\begin{array}{l}\text { Cortes et al, } \\
\text { NCT0066092015 }\end{array}$ & 1 & 2-60 mg daily & $\begin{array}{l}60, \text { resistant to } \\
\text { CML } \\
-43, \mathrm{CP} \\
-22, \mathrm{AP} / \mathrm{BP} \\
-12, \mathrm{~T} 3 \mathrm{I} 5 \mathrm{I} \\
\text { mutation }\end{array}$ & $\begin{array}{l}\text { - CHR } 98 \% \\
\text { MCyR } 72 \% \\
\text { MMR } 44 \% \\
\text { - CHR } 36 \% \\
\text { MCYR } 32 \% \\
\text { - CHR 100\% } \\
\text { MCYR } 92 \%\end{array}$ & $\begin{array}{l}\text { HTN } 24 \% \\
\text { MI, CVA, PVD, } \\
\text { VTE } 24 \%-48 \%\end{array}$ & $\begin{array}{l}\text { Rash (38\%) } \\
\text { GI SEs/pancreatitis } \\
(36 \%) \\
\text { Arthralgias (26\%) } \\
\text { Thrombocytopenia } \\
(25 \%)\end{array}$ \\
\hline & $\begin{array}{l}\text { Cortes et al, } \\
\text { NCTO I } 207440^{16}\end{array}$ & $\begin{array}{l}\text { II } \\
\text { PACE }\end{array}$ & $\begin{array}{l}45 \mathrm{mg} \text { daily } \\
\text { Dose reductions: } \\
30 \mathrm{mg} \text { daily (patients } \\
\text { without CMR) } \\
\text { I5 mg daily (patients } \\
\text { with CMR) }\end{array}$ & $\begin{array}{l}412 \text {, resistant or } \\
\text { intolerant to other } \\
\text { TKI } \\
-267, \mathrm{CP} \\
-83 \mathrm{AP} \\
-62 \mathrm{BP}\end{array}$ & $\begin{array}{l}\text { 3-year OS 78\% } \\
\text { PFS 60\% } \\
\text { - MCyR 56\% } \\
\text { CCyR } 46 \% \\
\text { MMR 34\% } \\
\text { - CHR 55\% } \\
\text { MCyR 39\% } \\
\text { - CHR 31\% } \\
\text { MCyR 23\% }\end{array}$ & As in Phase I & As in Phase I \\
\hline & $\begin{array}{l}\text { Lipton et al, } \\
\text { NCT0I } 650805^{22}\end{array}$ & $\begin{array}{l}\text { III } \\
\text { EPIC }\end{array}$ & $\begin{array}{l}\text { Ponatinib } 45 \mathrm{mg} \text { daily } \\
(n=155) \text { or imatinib } \\
400 \mathrm{mg} \text { daily }(n=152) \\
\text { until progression }\end{array}$ & $\begin{array}{l}\text { 307, newly } \\
\text { diagnosed }\end{array}$ & $\begin{array}{l}\text { MMR at } 5 \\
\text { months } 94 \%\end{array}$ & $\begin{array}{l}\text { MI 6\%-9\% } \\
\text { CVA 3\%-6\% } \\
\text { PVD 4\%-6\% } \\
\text { VTE 3\%-5\% } \\
\text { Five deaths }\end{array}$ & $\begin{array}{l}\text { Pancreatitis } 14 \% \\
\text { Thrombocytopenia } \\
12 \% \\
\text { Rash } 6 \%\end{array}$ \\
\hline & $\begin{array}{l}\text { Jain et al, } \\
\text { NCTOI } 570868^{23}\end{array}$ & II & $\begin{array}{l}45 \text { mg daily ( } n=43) \\
30 \text { mg daily }(n=8)\end{array}$ & $\begin{array}{l}\text { 5I, newly } \\
\text { diagnosed }\end{array}$ & $\begin{array}{l}\text { CCyR } 94 \% \\
\text { MMR } 50 \% \\
\text { CMR } 55 \%\end{array}$ & $\begin{array}{l}\text { HTN } 49 \% \\
\text { CVA } 10 \%\end{array}$ & $\begin{array}{l}\text { Myelosuppression } \\
29 \%\end{array}$ \\
\hline \multirow[t]{2}{*}{ ALL } & $\begin{array}{l}\text { Cortes et al, } \\
\text { NCT0066092015 } \\
\text { Cortes et al, } \\
\text { NCTOI } 207440^{16}\end{array}$ & $\begin{array}{l}\text { II } \\
\text { PACE }\end{array}$ & $\begin{array}{l}\text { 2-60 mg daily } \\
45 \mathrm{mg} \text { daily }\end{array}$ & $\begin{array}{l}\text { 32, resistant to } \\
\text { two TKls }\end{array}$ & $\begin{array}{l}\text { CHR } 41 \% \\
\text { MCyR } 47 \% \\
\text { CCyR } 38 \%\end{array}$ & As above & $\begin{array}{l}\text { As above } \\
\text { As above }\end{array}$ \\
\hline & Jabbour et $\mathrm{a}^{26}$ & II & $\begin{array}{l}\text { Hyper-CVAD plus } \\
\text { - Cycle I: Ponatinib } \\
45 \mathrm{mg} \text { daily } \\
\text { - Cycle } 2 \text { and beyond: } \\
\text { - Ponatinib } 30 \mathrm{mg} \\
\text { daily (patients without } \\
\text { CMR) } \\
\text { - Ponatinib I5 mg daily } \\
\text { (patients with CMR) }\end{array}$ & $\begin{array}{l}\text { 66, newly } \\
\text { diagnosed }\end{array}$ & $\begin{array}{l}\text { CCyR 100\% } \\
\text { MMR } 97 \% \\
\text { CMR 77\% } \\
\text { alloHCT 17\% }\end{array}$ & $\begin{array}{l}\text { HTN (I2\%) } \\
\text { Thrombotic } \\
\text { events (6\%) } \\
\text { MI (5\%) } \\
\text { Two deaths }\end{array}$ & $\begin{array}{l}\text { Infections (52\%) } \\
\text { LFT abnormalities } \\
(29 \%) \\
\text { Pancreatitis I8\% } \\
\text { Rash I4\% }\end{array}$ \\
\hline
\end{tabular}

Abbreviations: ALL, acute lymphoblastic leukemia; alloHCT, allogeneic hematopoietic cell transplantation; AP, accelerated phase; BP, blast phase; CCyR, complete cytogenetic response; $\mathrm{CHR}$, complete hematologic response; $\mathrm{CML}$, chronic myeloid leukemia; $\mathrm{CMR}$, complete molecular response; $\mathrm{CP}$, chronic phase; $\mathrm{CVA}$, cerebrovascular accident; CVAD, central venous access device; GI, gastrointestinal; HTN, hypertension; LFT, liver function test; MCyR, major cytogenetic response; MI, myocardial infarction; MMR, major molecular response; OS, overall survival; PFS, progression-free survival; PVD, peripheral vascular disease; SE, side effects; TKIs, tyrosine kinase inhibitors; VTE, venous thromboembolism.

pretreated patients with CML, including 267 patients in chronic phase who were either intolerant (16\%) or resistant to a second-line TKI (84\%), received ponatinib at a dose of $45 \mathrm{mg}$ daily. ${ }^{16}$ The T315I mutation was present in $24 \%$ of the patients with chronic phase CML. Forty-six percent of the patients achieved CCyR, 56\% MCyR, and 31\% MMR. Among patients with the T315I mutation, 72\% experienced an MCyR, $70 \%$ a CCyR, and 58\% an MMR. Importantly, responses occurred fast, 2.8-5.5 months after drug initiation. At 3-year follow-up, OS was $78 \%$, progression-free survival
(PFS) was $60 \%$, and $45 \%$ of patients remained on treatment. Reasons for discontinuation included progression (13\%) and intolerance (12\%), among others. Importantly, responses were durable despite dose reductions that were implemented due to emerging vascular side effects, with MCyR 75\%, CCyR 72\%, and MMR 61\%. ${ }^{17}$ Lipton et al published a metaanalysis in 2015 comparing the efficacy of ponatinib to that of second-generation TKIs administered to patients who were CML resistant or intolerant to at least one prior secondgeneration TKI. The estimated probability of CCyR was $60 \%$ 
with ponatinib vs $22 \%-26 \%$ with a second-generation TKI (95\% CI 52\%-68\%), while safety was not tested. ${ }^{21}$

The Phase III EPIC trial tested ponatinib as a frontline therapy for CML. The study included 307 newly diagnosed CML patients in chronic phase who were randomized to either ponatinib $45 \mathrm{mg}$ daily or imatinib $400 \mathrm{mg}$ daily. However, this study was terminated early due to the high frequency of vascular events reported in the ponatinib arm, not allowing assessment of the primary end point of MMR at 12 months, since only 23 patients reached that time point. Specifically, fatal myocardial infarctions (6\%-9\%), cerebrovascular events (3\%-6\%), peripheral vascular disease (4\%-6\%), and venous thromboembolism (3\%-5\%) were observed. Five deaths were attributed to vascular events resulting from ponatinib. The investigators concluded that responses to ponatinib were early, as $94 \%$ of patients in the ponatinib arm vs $68 \%$ of patients in the imatinib arm achieved an MMR after a median follow-up of 5 months. In addition, $31 \%$ of patients in the ponatinib arm vs $3 \%$ of patients in the imatinib arm achieved an MMR at 3 months. ${ }^{22}$

Around the same time, a Phase II single-arm trial accrued 51 newly diagnosed CML patients in chronic phase. Although the initial dose of ponatinib was $45 \mathrm{mg}$ daily, this was subsequently decreased due to side effects and the median dose ended up being $30 \mathrm{mg}$ daily. Similar to the EPIC trial, this trial had to be terminated early due to vascular side effects; however, the median follow-up was 22.7 months, which was significantly longer than in the EPIC trial. At 3 months, $90 \%$ of patients achieved CCyR and 50\% an MMR. After a median follow-up of 22.7 months, $94 \%$ of patients achieved a CCyR and $55 \%$ a complete molecular response (CMR). There were no deaths during the study period and none of the patients progressed to blast phase..$^{23}$

Other trials are currently ongoing, such as the Phase $1 / 2$ NCT01667133 trial that is investigating the use of ponatinib in Japanese patients with Ph+ALL and CML who have failed a second-line TKI. Some results have already been reported showing an MCyR at 12 months of $65 \%$ in patients with chronic phase CML and a major hematologic response at 6 months of $61 \%$ in patients with advanced disease. ${ }^{24}$

\section{Efficacy of ponatinib in ALL}

In ALL, ponatinib has been approved by FDA for subsequent therapy of patients who are either intolerant or resistant to another TKI. Ponatinib has also been tested as a frontline therapy for newly diagnosed $\mathrm{Ph}+\mathrm{ALL}$ in combination with standard chemotherapy showing some remarkable responses. ${ }^{25}$ However, prospective studies that directly compare different TKIs in the treatment of Ph+ ALL have not been conducted.

The initial Phase I trial by Cortes et al included five patients with $\mathrm{Ph}+\mathrm{ALL}$. However, their clinical outcomes were not reported separately from those of patients with accelerated or blast phase CML. ${ }^{15}$ The PACE Phase II trial included 32 adult patients with Ph+ ALL who were resistant to at least two prior TKIs. The initial response rates were CHR of $41 \%$, MCyR of $47 \%$, and CCyR of $38 \%$. However, early relapses were noted leading to a median OS of 8 months. ${ }^{16}$

Recently, Jabbour et al reported the results of a Phase II single-center study testing the combination of ponatinib with hyper-cyclophosphamide, vincristine, doxorubicin and dexamethasone (CVAD) in newly diagnosed Ph+ ALL. ${ }^{26}$ The authors recently updated the results of the trial at 3-year follow-up. All the 66 patients who were treated with ponatinib achieved CCyR, while 97\% achieved MMR, and 77\% achieved CMR. After a median follow-up of 32 months, $78 \%$ were in complete remission (CR) and $17 \%$ received allogeneic hematopoietic cell transplantation (alloHCT). The 3-year OS was $77 \%$. Thirty-eight patients remain on ponatinib while reasons for discontinuation in the rest were disease relapse (7 patients), alloHCT (11 patients), and death (8 patients). Importantly, the dose of ponatinib was decreased from 45 mg daily on cycle 1 to either $30 \mathrm{mg}$ daily for patients who had not achieved a CMR or $15 \mathrm{mg}$ daily for patients in CMR due to reports of vascular side effects. ${ }^{27}$

Investigators from the same group performed a comparison of patients with newly diagnosed $\mathrm{Ph}+\mathrm{ALL}$ who had been treated either with hyper-CVAD plus dasatinib or hyper-CVAD plus ponatinib as part of a different Phase II clinical trial. With propensity score matching, the authors concluded that the combination of ponatinib with chemotherapy was superior to that of dasatinib with chemotherapy owing to the higher 3 -year OS ( $83 \%$ vs $56 \%, p=0.001)$ and higher PFS (69\% vs $46 \%, p=0.003) .^{28}$

Finally, an Italian Phase II trial (NCT01641107) is currently ongoing and is testing ponatinib as a frontline treatment in elderly patients or those who are not candidates for chemotherapy and ASCT. Thirteen patients have been enrolled so far, and all have achieved a CHR.

\section{Side-effect profile}

Despite the remarkable responses observed in the above discussed trials, the use of ponatinib has also been associated with serious adverse events, which led to the temporary withdrawal of the drug from the market by the FDA in $2013 .{ }^{29}$ 
The most common side effects reported in the Phase I and II trials were rashes (38\%), GI side effects $(36 \%$; including pancreatitis), thrombocytopenia (25\%), arthralgia (26\%), and fatigue. In addition, grade 3 or 4 thrombocytopenia was more common with ponatinib (12\%) compared with imatinib (7\%). At a median follow-up of 4 years, $25 \%$ of patients who were part of the Phase I clinical trial discontinued the drug due to side effects. ${ }^{15,16}$

More importantly, extended follow-up of the above trials revealed high frequency of serious vascular events, including myocardial infarctions, strokes, peripheral vascular disease, and venous thromboembolism, which ranged between $24 \%$ and $48 \%$. In addition, hypertension occurred in $24 \%$ of treated patients. The median time to event was 13.8 months for arterial events and 18.4 months for venous events, and 9\% of patients discontinued treatment due to a vascular event. ${ }^{30}$ Toxicity was dose dependent and the pharmacokinetics of ponatinib were similar for doses ranging between 30 and 45 mg daily. ${ }^{31}$ However, the 2-year OS did not differ between patients who had an arterial thrombotic event and patients who did not. ${ }^{16,32}$ In the EPIC trial, 7\% of patients receiving ponatinib vs $2 \%$ of patients receiving imatinib experienced arterial occlusive events $(p=0.052)$. Subsequent analysis demonstrated that patients in the ponatinib arm who developed cardiovascular toxicity had at least one cardiovascular risk factor. However, no deaths were attributed to the use of ponatinib. ${ }^{22}$ Similarly, all patients in the Phase II trial testing ponatinib as a frontline therapy in newly diagnosed CML were taken off trial. Out of 51 patients, 38 were taken off due to high risk for arterial thrombosis and 13 due to side effects. Half of the patients had cardiovascular events, with hypertension being the most common in $29 \%$ of patients and seven experienced arterial ischemic events. Treatment interruptions were required in $85 \%$ and dose reductions in $88 \%$, and no deaths were reported. ${ }^{23}$

Finally, at the most recent update of the Phase II trial testing ponatinib in the frontline treatment of ALL, two deaths from myocardial infarctions were attributed to the use of ponatinib. Following the emergence of cardiovascular side effects, the protocol was amended and the dose of ponatinib was decreased to either 15 or $30 \mathrm{mg}$ daily depending on whether the patient had achieved CMR or not, respectively. ${ }^{26}$ Interestingly, a recent meta-analysis of all randomized trials comparing all the different generation of TKIs demonstrated higher cardiovascular risk with newer TKIs when compared to imatinib, and $4.78 \%$ of patients receiving a new generation TKI experienced an arterial occlusive event vs $0.96 \%$ of patients receiving imatinib. Ponatinib was associated with higher rates of arterial events compared with imatinib (odds ratio $=3.26$, 95\% CI 1.12-9.50). ${ }^{30}$

Given the fact that dose reductions were required in previous trials due to severe cardiovascular side effects, an ongoing multicenter randomized Phase II trial (NCT02467270) is aiming to characterize the efficacy and safety of different ponatinib starting doses $(15,30$, and $45 \mathrm{mg})$ in patients with CML resistant to at least two prior TKIs. The rationale behind the efficacy of lower doses is based on preclinical data demonstrating that ponatinib doses of $15 \mathrm{mg}$ are adequate to achieve the minimum required plasma concentration that is sufficient to treat all known mutations that confer resistance. ${ }^{15,31}$ In addition, toxicity was dose dependent in the early phase clinical trials, which justifies attempts to determine the minimum required dose. ${ }^{15,16}$

The mechanism of the cardiovascular side effects is not clear. Ponatinib is known to inhibit the VEGF, FGF, and PDGF pathways, and it is likely that it causes upregulation of adhesion molecules and proinflammatory cytokines as suggested by preclinical data in cell lines. ${ }^{33}$ However, because of the relatively short interval between the exposure to ponatinib and the incidence of the vascular side effects, a direct effect of ponatinib on the endothelial cells is possible. ${ }^{34}$ In addition, preclinical data have suggested that ponatinib enhances the expression of proteins that promote plaque formation. ${ }^{35}$ Other potential mechanisms include inhibition of mast cell differentiation, which is required for vascular repair, through inhibition of KIT. ${ }^{36}$

Platelet dysfunction associated with the use of ponatinib in patients with CML has been described. Five patients with CML who received ponatinib for over 2 weeks for TKI-resistant disease were analyzed and were found to have a prolonged closure time with platelet functional analyzer (PFA) 100. However, none of these patients experience clinically significant bleeding. ${ }^{37}$ Subsequently, the investigators of the PACE trial conducted a retrospective review of the charts of 80 patients who were treated with ponatinib for chronic phase CML. Although nine patients experienced bleeding episodes, none of those were attributed to ponatinib or required dose interruptions. In addition, patients with a prior history of bleeding or who were on anticoagulation did not experience bleeding, suggesting that ponatinib is safe in this setting. ${ }^{38}$ The mechanism of platelet dysfunction is thought to be due to inhibition of kinases, including SFK, LYN, and FYN that are implicated in early platelet activation. ${ }^{37,38}$ 


\section{Patient selection}

Although ponatinib is associated with deep and durable responses, high discontinuation rates have been observed due to side effects, which stresses the importance of careful patient selection. ${ }^{39}$ Most cardiovascular events in the PACE trial occurred in patients with additional risk factors, including age $>65$ years, diabetes, and hyperlipidemia. Half of the patients that developed cardiovascular events had a history of previous cardiac disease, whereas the percentage of patients with history of cardiac disease that did not experience cardiovascular side effects was much lower at $17 \%{ }^{16,40}$ A recent meta-analysis reviewed all the patient data from the Phase I, PACE and EPIC trials. On multivariate analysis, dose intensity correlated with the cardiovascular risk. Specifically, each $15 \mathrm{mg}$ dose reduction was calculated to result in a predicted $40 \%$ reduction in the risk of arterial thrombosis. Older age, diabetes, higher dose, history of ischemia, longer time since diagnosis, higher neutrophil and platelet counts were identified as independent predictors of cardiovascular risk. ${ }^{16,32}$ Thus, assessment of cardiovascular risk at baseline is required prior to initiation of ponatinib in order to identify those patients who are likely to have a vascular adverse event and in whom the risk to benefit ratio does not justify initiation of the medication. ${ }^{39}$ Some experts recommend excluding patients with previous myocardial infarction, stroke, and peripheral arterial disease, and close monitoring of blood pressure. ${ }^{41}$ Incorporation of the airway, breathing, circulation, disability, exposure (ABCDE) algorithm of cardiovascular risk assessment has also been proposed, which is routinely used for breast cancer survivors. ${ }^{42,43}$ The steps involved in this algorithm are the following: 1) awareness of signs and symptoms of cardiovascular disease, 2) aspirin use in select patients, 3) ankle-brachial index measurement at baseline and follow-up, 4) blood pressure control, 5) cigarette cessation, 6) cholesterol monitoring and treatment, 7) diabetes monitoring and treatment, and 8) diet and exercise. ${ }^{44}$

Interestingly, in vitro data indicate that the minimum required plasma concentration of $40 \mathrm{nmol} / \mathrm{L}$ can be reached with ponatinib doses $<45 \mathrm{mg}$ daily and that even a dose of $15 \mathrm{mg}$ daily is sufficient to treat all known mutations that confer resistance. ${ }^{31}$ In addition, compound mutations are not major drivers of resistance to ponatinib in chronic phase CML. ${ }^{20}$ Thus, lower doses may be sufficient and safer. Limited data from the PACE trial are available from patients who reduced their ponatinib dose to either $15 \mathrm{mg}$ daily after achieving a CMR or $30 \mathrm{mg}$ daily if they had not achieved a CMR. The majority of patients have had durable responses even after dose reductions were implemented and a low incidence of cardiovascular side effects. ${ }^{16}$ The same dose reductions were implemented in the ALL trial by Jabbour et al who tested ponatinib with hyper-CVAD as frontline therapy. Importantly, despite the dose reductions beginning at cycle 2, the responses were durable with 58 out of 66 patients remaining in CR after a median follow-up of 32 months. ${ }^{26,27}$ Overall, since ponatinib was first introduced, $33 \%$ of patients have received a dose of $30 \mathrm{mg}$ daily and $17 \%$ a dose of $15 \mathrm{mg}$ daily. Two ongoing studies are investigating the effects of these lower doses as starting doses (NCT02467270 and NCT02627677).

With regards to the patients' age, this has been identified as an independent predictor of cardiovascular risk. ${ }^{32}$ However, since the $\mathrm{Ph}$ chromosome is more common in elderly patients with ALL who are often unable to tolerate intensive chemotherapy, TKIs and, specifically, ponatinib may constitute the basis of treatment for this patient population. There is clinical evidence that some patients can achieve a durable response with TKIs and corticosteroids alone..$^{45,46}$ On the other hand, in younger patients, ponatinib may play an important role as a bridge to transplant.

With regards to prior transplantation, ponatinib has been reported to result in deep responses but also severe graftversus-host disease (GVHD). Two cases were reported recently who were treated with ponatinib for posttransplant relapse, one with ALL and another with CML. Although both patients achieved deep molecular responses, they also developed cutaneous GVHD which required medication discontinuation in the patient with CML. ${ }^{47}$ Skin GVHD following initiation of ponatinib for posttransplant relapses has also been described in other case reports, suggesting a potential role of ponatinib to enhance the graft-versus-leukemia effect. ${ }^{48,49}$ Overall, 43 patients have received ponatinib for posttransplant relapses in the early phase clinical trials; however, their clinical outcomes and side-effect profile have not been reported separately. ${ }^{15,16}$

An important question is whether the use of ponatinib in patients with the T315I mutation balances the poor prognosis associated with the mutation and leads to improved outcomes without alloHCT. Although no prospective studies have compared the outcomes of patients with the T315I mutation who received ponatinib to those of patients who received alloHCT, a recent retrospective study compared the outcomes of patients who were treated as part of the PACE trial with those of patients who underwent alloHCT in the European Group for Blood and Marrow Transplantation registry. The authors concluded that ponatinib led to higher OS compared with alloHCT for patients with chronic phase CML (48-month OS, $73 \%$ vs $56 \%, p=0.013$, respectively) 
but lower OS in patients with blast crisis CML (hazard ratio $[\mathrm{HR}]=2.29[95 \% \mathrm{CI}, 1.08-4.82, p=0.030])$ and patients with Ph-positive ALL $(\mathrm{HR}=2.77$ [95\% CI, 0.73-1 0.56, $p=0.146]) .{ }^{50}$ This finding suggests that ponatinib may lead to better outcomes among patients with the T315I mutation when administered for chronic phase CML and abrogate the future need for transplant.

\section{Future perspectives}

Although ponatinib has demonstrated some remarkable results in trials conducted in both $\mathrm{CML}$ and $\mathrm{Ph}$-positive ALL, its role in the management of these patients remains unclear due to the risks associated with its use. Thus, more studies are required to evaluate the efficacy and safety of lower ponatinib doses. An in vitro concentration of $40 \mathrm{nM}$ is known to be required for the inhibition of emergence of resistant clones, but higher concentrations may be required for treatment of the T315I mutation, and biomarkers that could predict the emergence of resistance are currently lacking. ${ }^{14} \mathrm{~A}$ recent study conducted in patients with chronic phase CML showed that those with the T315I mutation had better outcomes compared with patients with several low-level mutations, likely due to the presence of low-level mutations predisposing to the development of TKI-resistant clones. ${ }^{51}$ Thus, high-sensitivity genetic analysis techniques are required to detect low-level mutations before treatment as these patients would likely benefit from treatment with ponatinib. The early identification of mutation detection through new gene sequencing techniques is an area of active research. Ultra-deep sequencing has been compared to conventional Sanger sequencing which requires 10\%-20\% expansion of the resistant clone and was able to detect mutations at $1 \%-2 \%$ and as soon as 3 months earlier than with conventional sequencing. ${ }^{52}$

In order to decrease the side effects associated with TKIs, several approaches have been proposed from different experts. Imatinib is still considered the first choice for frontline therapy in many institutions with physicians switching to a newer generation TKI after early imatinib failure. Bosutinib is a newer generation TKI with a more tolerable cardiovascular effect profile, and many experts use it as an alternative for higher risk patients. Discontinuation of TKIs after achievement of CMR has also been suggested. ${ }^{53}$ In addition, alternating between different generation TKIs in order to decrease the time of exposure to ponatinib has been suggested. ${ }^{54}$ Further studies are required to directly compare different TKIs and determine the best sequence of treatment as well as the optimal duration of therapy. Finally, once vascular events occur, consideration of the need to continue ponatinib should be made as well as optimization of other cardiovascular risk factors.

In addition, the role of ponatinib in elderly patients has not been completely elucidated. Since old age has been described as an independent predictor of high cardiovascular risk, ponatinib may not be well tolerated by elderly patients. On the other hand, intense chemotherapy used for the treatment of ALL may not be tolerated by elderly patients or those with comorbidities, as hyper-CVAD has been associated with high mortality rates during or after treatment completion in elderly patients. One alternative in this patient population could be the combination of ponatinib with corticosteroids and reduced intensity chemotherapy to decrease the rates of recurrence. There is also rationale of trying to replace intensive chemotherapy with safer and effective treatment strategies in the elderly patient population. Novel agents, such as the monoclonal antibody-chemotherapy conjugate, inotuzumab ozogamicin, and the bispecific antibody, blinatumomab, have demonstrated significant results in Ph-positive ALL and could potentially be tested in combination with ponatinib in future trials. Finally, use of ponatinib as a single agent could be an option in elderly or unfit patients. The Gruppo Italiano Malattie Ematologiche dell'Adulto has tested the combination of dasatinib plus steroids and reported 20-month PFS rates of $51 \%$ and OS of $69 \% .{ }^{55}$ Another Italian study, which is ongoing, is investigating the safety and efficacy of ponatinib in elderly patients as well as young patients who are not candidates for intensive chemotherapy. ${ }^{56}$

Finally, the role and safety of ponatinib posttransplant remains unclear. Imatinib has been used in patients who are minimal residual disease positive after transplant ${ }^{57}$ as well as for molecular relapses posttransplant and has led to high response rates. ${ }^{58}$ Although a total of 43 patients have received ponatinib in the posttransplant setting, detailed data regarding their outcomes have not been reported, and case reports of such patients suggest high incidence of GVHD, in some cases necessitating medication discontinuation. ${ }^{48,49}$ Thus, it remains unknown whether a select group of patients could benefit from posttransplant treatment with ponatinib for either prevention or treatment of molecular relapse. ${ }^{59}$

\section{Author contributions}

Both the authors were involved in the manuscript preparation. All authors contributed toward data analysis, drafting and revising the paper and agree to be accountable for all aspects of the work.

\section{Disclosure}

The authors report no conflicts of interest in this work. 


\section{References}

1. Shuai K, Halpern J, ten Hoeve J, Rao X, Sawyers CL. Constitutive activation of STAT5 by the BCR-ABL oncogene in chronic myelogenous leukemia. Oncogene. 1996;13(2):247-254.

2. Raitano AB, Halpern JR, Hambuch TM, Sawyers CL. The BCR-ABL leukemia oncogene activates Jun kinase and requires Jun for transformation. Proc Natl Acad Sci USA. 1995;92(25):11746-11750.

3. Ottmann OG, Pfeifer H. Management of Philadelphia chromosomepositive acute lymphoblastic leukemia (Ph+ ALL). Hematol Am Soc Hematol Educ Prog. 2009:371-381.

4. Gotz G, Weh HJ, Walter TA, et al. Clinical and prognostic significance of the Philadelphia chromosome in adult patients with acute lymphoblastic leukemia. Ann Hematol. 1992;64(2):97-100.

5. Gleissner B, Gokbuget N, Bartram CR, et al. Leading prognostic relevance of the BCR-ABL translocation in adult acute B-lineage lymphoblastic leukemia: a prospective study of the German Multicenter Trial Group and confirmed polymerase chain reaction analysis. Blood. 2002;99(5):1536-1543.

6. Sive JI, Buck G, Fielding A, et al. Outcomes in older adults with acute lymphoblastic leukaemia (ALL): results from the international MRC UKALL XII/ECOG2993 trial. Br J Haematol. 2012;157(4):463-471.

7. Hochhaus A, Larson RA, Guilhot F, et al. Long-term outcomes of imatinib treatment for chronic myeloid leukemia. N Engl J Med. 2017; 376(10):917-927.

8. Ernst T, La Rosee P, Muller MC, Hochhaus A. BCR-ABL mutations in chronic myeloid leukemia. HematolOncolClinNAm. 2011;25(5):9971008, v-vi.

9. Jabbour E, Kantarjian HM, Saglio G, et al. Early response with dasatinib or imatinib in chronic myeloid leukemia: 3-year follow-up from a randomized phase 3 trial (DASISION). Blood. 2014;123(4): 494-500.

10. Larson RA, Hochhaus A, Hughes TP, et al. Nilotinib vs imatinib in patients with newly diagnosed Philadelphia chromosome-positive chronic myeloid leukemia in chronic phase: ENESTnd 3-year followup. Leukemia. 2012;26(10):2197-2203.

11. Lee S, Kim YJ, Min CK, et al. The effect of first-line imatinib interim therapy on the outcome of allogeneic stem cell transplantation in adults with newly diagnosed Philadelphia chromosome-positive acute lymphoblastic leukemia. Blood. 2005;105(9):3449-3457.

12. Mizuta S, Matsuo K, Nishiwaki S, et al. Pretransplant administration of imatinib for allo-HSCT in patients with BCR-ABL-positive acute lymphoblastic leukemia. Blood. 2014;123(15):2325-2332.

13. Lu L, Saunders VA, Leclercq TM, Hughes TP, White DL. Ponatinib is not transported by ABCB1, ABCG2 or OCT-1 in CML cells. Leukemia. 2015;29(8):1792-1794.

14. O'Hare T, Shakespeare WC, Zhu X, et al. AP24534, a pan-BCRABL inhibitor for chronic myeloid leukemia, potently inhibits the T315I mutant and overcomes mutation-based resistance. Cancer Cell. 2009;16(5):401-412.

15. Cortes JE, Kantarjian H, Shah NP, et al. Ponatinib in refractory Philadelphia chromosome-positive leukemias. $N$ Engl J Med. 2012; 367(22):2075-2088.

16. Cortes JE, Kim DW, Pinilla-Ibarz J, et al. A phase 2 trial of ponatinib in Philadelphia chromosome-positive leukemias. N Engl J Med. 2013; 369(19):1783-1796.

17. Cortes J. Ponatinib efficacy and safety in heavily pretreated leukemia patients: 3 year results of the PACE trial. Haematologica. 2015;100(Supp11):64.

18. Nicolini FE, Ibrahim AR, Soverini S, et al. The BCR-ABLT315I mutation compromises survival in chronic phase chronic myelogenous leukemia patients resistant to tyrosine kinase inhibitors, in a matched pair analysis. Haematologica. 2013;98(10):1510-1516.

19. Miller GD, Bruno BJ, Lim CS. Resistant mutations in CML and $\mathrm{Ph}(+)$ ALL - role of ponatinib. Biologics. 2014;8:243-254.

20. Deininger MW, Hodgson JG, Shah NP, et al. Compound mutations in BCR-ABL1 are not major drivers of primary or secondary resistance to ponatinib in CP-CML patients. Blood. 2016;127(6):703-712.
21. Lipton JH, BrydenP, Sidhu MK, et al. Comparative efficacy of tyrosine kinase inhibitor treatments in the third-line setting, for chronic-phase chronic myelogenous leukemia after failure of second-generation tyrosine kinase inhibitors. Leuk Res. 2015;39(1):58-64.

22. Lipton JH, Chuah C, Guerci-Bresler A, et al. Ponatinib versus imatinib for newly diagnosed chronic myeloid leukaemia: an international, randomised, open-label, phase 3 trial. Lancet Oncol. 2016;17(5):612-621.

23. Jain P, Kantarjian H, Jabbour E, et al. Ponatinib as first-line treatment for patients with chronic myeloid leukaemia in chronic phase: a phase 2 study. Lancet Haematol. 2015;2(9):e376-e383.

24. Tojo A, Kyo T, Yamamoto K, et al. Ponatinib in Japanese patients with Philadelphia chromosome-positive leukemia, a phase $1 / 2$ study. Int $J$ Hematol. 2017;106(3):385-397.

25. Jabbour E, Kantarjian H, O'Brien S, et al. The achievement of an early complete cytogenetic response is a major determinant for outcome in patients with early chronic phase chronic myeloid leukemia treated with tyrosine kinase inhibitors. Blood. 2011;118(17):4541-4546; quiz 4759.

26. Jabbour E, Kantarjian H, Ravandi F, et al. Combination of hyper-CVAD with ponatinib as first-line therapy for patients with Philadelphia chromosome-positive acute lymphoblastic leukaemia: a single-centre, phase 2 study. Lancet Oncol. 2015;16(15):1547-1555.

27. Maiti A, Kantarjian H. Hyper-CVAD plus ponatinib as frontline therapy in Philadelphia chromosome-positive acute lymphoblastic leukemia: updated results of a phase II trial. Clin Lymphoma Myeloma Leuk. 2017; 17:S257-S258.

28. Sasaki K, Jabbour EJ, Ravandi F, et al. Hyper-CVAD plus ponatinib versus hyper-CVAD plus dasatinib as frontline therapy for patients with Philadelphia chromosome-positive acute lymphoblastic leukemia: a propensity score analysis. Cancer. 2016;122(23):3650-3656.

29. Gainor JF, Chabner BA. Ponatinib: accelerated disapproval. Oncologist. 2015;20(8):847-848.

30. Haguet H, Douxfils J, Mullier F, Chatelain C, Graux C, Dogne JM. Risk of arterial and venous occlusive events in chronic myeloid leukemia patients treated with new generation BCR-ABL tyrosine kinase inhibitors: a systematic review and meta-analysis. Expert Opin Drug Saf. 2017;16(1):5-12.

31. Cortes JE, Talpaz M, Kantarjian H. Ponatinib in Philadelphia chromosome-positive leukemias. N Engl J Med. 2014;370(6):577.

32. Dorer DJ, Knickerbocker RK, Baccarani M, et al. Impact of dose intensity of ponatinib on selected adverse events: multivariate analyses from a pooled population of clinical trial patients. Leuk Res. 2016;48:84-91.

33. Rivera VM, Pritchard JR, Gonzalvez F et al. Comparative TKI profiling analyses to explore potential mechanisms of ponatinib-associated arterial adverse events. Blood. 2014;124:1784A.

34. Valent P, Hadzijusufovic E, Schernthaner GH, Wolf D, Rea D, le Coutre P. Vascular safety issues in CML patients treated with BCR/ABL1 kinase inhibitors. Blood. 2015;125(6):901-906.

35. Hadzijusufovic E, Kirchmair R, Theurl M, et al. Ponatinib exerts multiple effects on vascular endothelial cells: possible mechanisms and explanations for the adverse vascular events seen in CML patients treated with ponatinib. Blood. 2016;128:1883.

36. Valent $\mathrm{P}$, Baghestanian M, Bankl HC, et al. New aspects in thrombosis research: possible role of mast cells as profibrinolytic and antithrombotic cells. Thromb Haemost. 2002;87(5):786-790.

37. Neelakantan P, Marin D, Laffan M, Goldman J, Apperley J, Milojkovic D. Platelet dysfunction associated with ponatinib, a new pan BCR-ABL inhibitor with efficacy for chronic myeloid leukemia resistant to multiple tyrosine kinase inhibitor therapy. Haematologica. 2012;97(9):1444.

38. Nazha A, Romo CG, Kantarjian H, Cortes J. The clinical impact of ponatinib on the risk of bleeding in patients with chronic myeloid leukemia. Haematologica. 2013;98(10):e131.

39. Poch Martell M, SibaiH, Deotare U, Lipton JH. Ponatinib in the therapy of chronic myeloid leukemia. Expert Rev Hematol. 2016;9(10):923-932.

40. MassaroF, MolicaM, Breccia M. Ponatinib: a review of efficacy and safety. Curr Cancer Drug Targets. Epub 2017 Oct 2.

41. Breccia M, Pregno P, Spallarossa P, et al. Identification, prevention and management of cardiovascular risk in chronic myeloid leukaemia patients candidate to ponatinib: an expert opinion. Ann Hematol. 2017;96(4): $549-558$. 
42. Moslehi JJ, Deininger M. Tyrosine kinase inhibitor-associated cardiovascular toxicity in chronic myeloid leukemia. J Clin Oncol. 2015; 33(35):4210-4218.

43. Montazeri K, Unitt C, Foody JM, Harris JR, Partridge AH, Moslehi J. ABCDE steps to prevent heart disease in breast cancer survivors. Circulation. 2014;130(18):e157-e159.

44. Hsu S, Ton VK, Dominique Ashen M, et al. A clinician's guide to the ABCs of cardiovascular disease prevention: the Johns Hopkins Ciccarone Center for the Prevention of Heart Disease and American College of Cardiology Cardiosource Approach to the Million Hearts Initiative. Clin Cardiol. 2013;36(7):383-393.

45. Baccarani M, Deininger MW, Rosti G, et al. European Leukemia Net recommendations for the management of chronic myeloid leukemia: 2013. Blood. 2013;122(6):872-884.

46. Ravandi F, Kebriaei P. Philadelphia chromosome-positive acute lymphoblastic leukemia. Hematol Oncol Clin North Am. 2009;23(5):10431063, vi.

47. Hirschbuehl K, Rank A, Pfeiffer T, et al. Ponatinib given for advanced leukemia relapse after allo-SCT. Bone Marrow Transplant. 2015;50(4):599-600.

48. Petrungaro A, Gentile M, Mazzone C, et al. Ponatinib-induced graftversus-host disease/graft-versus-leukemia effect in a patient with Philadelphia-positive acute lymphoblastic leukemia without the T315I mutation relapsing after allogeneic transplant. Chemotherapy. 2017;62(6):353-356.

49. Renzi D, Marchesi F, De Angelis G, et al. Ponatinib induces a persistent molecular response and graft-versus-host disease/graft-versus-leukemia effect in a patient with Philadelphia-positive acute lymphoblastic leukemia with a T315I mutation following early relapse after allogeneic transplant. Chemotherapy. 2017;62(1):58-61.

50. Nicolini FE, Basak GW, Kim DW, et al. Overall survival with ponatinib versus allogeneic stem cell transplantation in Philadelphia chromosome-positive leukemias with the T315I mutation. Cancer. 2017;123(15):2875-2880.
51. Parker WT, Yeung DT, Yeoman AL, et al. The impact of multiple low-level BCR-ABL1 mutations on response to ponatinib. Blood. 2016;127(15):1870-1880.

52. Baer C, Kern W, Koch S, et al. Ultra-deep sequencing leads to earlier and more sensitive detection of the tyrosine kinase inhibitor resistance mutation T315I in chronic myeloid leukemia. Haematologica. 2016;101(7):830-838.

53. Mahon FX, Rea D, Guilhot J, et al. Discontinuation of imatinib in patients with chronic myeloid leukaemia who have maintained complete molecular remission for at least 2 years: the prospective, multicentre Stop Imatinib (STIM) trial. Lancet Oncol. 2010;11(11):1029-1035.

54. Valent P, Herndlhofer S, Schneeweiss M, et al. TKI rotation-induced persistent deep molecular response in multi-resistant blast crisis of $\mathrm{Ph}+$ CML. Oncotarget. 2017;8(14):23061-23072.

55. Foa R, Vitale A, Vignetti M, et al. Dasatinib as first-line treatment for adult patients with Philadelphia chromosome-positive acute lymphoblastic leukemia. Blood. 2011;118(25):6521-6528.

56. Malagola M, Papayannidis C, Baccarani M. Tyrosine kinase inhibitors in $\mathrm{Ph}+$ acute lymphoblastic leukaemia: facts and perspectives. Ann Hematol. 2016;95(5):681-693.

57. Carpenter PA, Snyder DS, Flowers ME, et al. Prophylactic administration of imatinib after hematopoietic cell transplantation for high-risk Philadelphia chromosome-positive leukemia. Blood. 2007;109(7): 2791-2793.

58. Wassmann B, Pfeifer H, Stadler M, et al. Early molecular response to posttransplantation imatinib determines outcome in MRD+ Philadelphia-positive acute lymphoblastic leukemia (Ph+ ALL). Blood. 2005;106(2):458-463.

59. Short NJ, Kantarjian H, Jabbour E, Ravandi F. Which tyrosine kinase inhibitor should we use to treat Philadelphia chromosomepositive acute lymphoblastic leukemia? Best Pract Res Clin Haematol. 2017;30(3):193-200.
Blood and Lymphatic Cancer: Targets and Therapy

\section{Publish your work in this journal}

Blood and Lymphatic Cancer: Targets and Therapy is an international peer-reviewed, open access journal focusing on blood and lymphatic cancer research, identification of therapeutic targets and the optimal use of preventative and integrated treatment interventions to achieve improved outcomes, enhanced survival and quality of life for the

\section{Dovepress}

cancer patient. The manuscript management system is completely online and includes a very quick and fair peer-review system. Visit http://www.dovepress.com/testimonials.php to read real quotes from published authors.

Submit your manuscript here: https://www.dovepress.com/blood-and-lymphatic-cancer-targets-and-therapy-journal 